\title{
An Empirical Study on Regional Differences of Higher Education Financial Aid in China*
}

\author{
ZHAN Hong-yi \\ Renmin University of China, Beijing, China
}

\begin{abstract}
This paper uses empirical data to examine the issue of fairness of higher education student financial aid in China, noting different levels of regional economic development as the reason to explain the wide differences in available financial resources for student aid. Government efforts aimed at reducing the gap in recent years is discussed.
\end{abstract}

Keywords: regional differences, higher education, financial aid, China

\section{Introduction}

In recent years, with the rapid growth of China's economy, China's higher education students funding system has been developed and perfected. The system of student funding on both state and university levels has been established, which mainly including: student loan system mainly based on state student loan, financial aid system mainly awarded by state grants and scholarships, state financial allocation, school self-organizing part-time job facilitating system, etc. In addition, many colleges and universities set up alumni and social organizations grants and scholarships. The government also complements and improves the subsidy system of higher education through various forms, including free-charge normal school students, "green passage" policy, and national student loan compensatory system.

In 2000, some full-time normal colleges and universities began to build "green passage" system, if the admitted freshmen have a family economic hardship, they can enter a school without pay tuition first, but funded by the school and other departments (Ding, Jiang, \& Yang, 2009). In 2007, the state began to implement free normal education, six subordinate normal universities admitted the outstanding high school graduates who participated in the early batch of the college entrance examination and give them free professional education (Rong \& Liu, 2012). In 2009, the national student loan compensatory system was introduced. After many years of efforts, China has formed a relatively perfect system of higher education student funding.

Since the beginning of the new century, the total amount of China's higher education student funding and the number of recipients has increased rapidly, the funding categories have been diversified, and the funding sources have been enriched. However, there are still some problems of regional differences and uneven distribution of resources among the higher education students funding system in China. There is a certain degree of difference between the higher education funding standards among the provinces, which is not only unfair, contrary to the idea of educational fairness, but also restricts the overall development of China's higher education. Therefore, this paper attempts to study the regional differences of China's higher education students

\footnotetext{
* Supported by the Fundamental Research Funds for the Central Universities, and the Research Funds of Renmin University of China.

ZHAN Hong-yi, Ph.D., Professor, School of Education, Renmin University of China.
} 
funding system from an empirical point of view, to analyze the influencing factors resulted in this difference in depth as well as the existence of the education fairness problems behind this phenomenon.

\section{Data Selection Basis and Sources}

\section{Data Selection Basis}

In 1997, China fully implemented the cost-sharing educational policy, which ended the double-track pricing system of tuition for many years (Prashant, Song, \& Wei, 2011). Since 1999, China has gradually formed a five-in-one hybrid funding system for "awards, assistance, loans, supplements, and subtractions." Therefore, this study selected data of higher education students funding in 2000-2013 ${ }^{1}$ to do empirical research about our country's higher education students support, to build the index evaluation system, compare our country's higher education students funded situation in historical and regional differences, and discuss our country's higher education fairness in the process of student financial assistance.

This paper regards the higher education per student funding in each region as the main research object and the equal degree of higher education per student funding represents the fairness of Chinese higher education student support degree, which has the following main basis.

First of all, the amount of higher education per student funding is the total number of higher education students funding in general colleges and universities divided by the number of students in general colleges and universities. After doing this, the difference in the amount of students funding due to the difference in the number of higher education students is avoided. Moreover, the amount of higher education per student funding to some extent represents the average level of the higher education students funding in the region, with a certain degree of representation, can be used to measure the fairness of the distribution of educational resources in the region.

The amount of higher education per student funding $=$
$\frac{\text { the total number of higher education students funding in general colleges and universities }}{\text { the number of students in general colleges and universities }}$

Secondly, China is a country with a vast territory. There is a large difference in the development of economic and social development within the country and there is a very significant imbalance in the distribution of higher education resources. For example, the number and quality of higher education schools in Beijing, Shanghai, Hubei, and Shanxi have an absolute advantage, while Qinghai, Gansu, Tibet, and other regions at a disadvantage. On the other hand, higher education is different from compulsory education and it is not target at the absolute fairness and equalization. Therefore, it is difficult to use a unified standard or a single indicator of higher education fair measurement. Then, this article will focus on the object of study on the fairness of funding for higher education students. Based on the above, we know that higher education student funding is to make up for the uneven and unfair defects in the development of higher education, to provide financial support for disadvantaged students in terms of economic status. Therefore, higher education student funding should be maintained within a relatively balanced range, in order to maintain the fairness of funding for higher education students. In summary, although it is difficult to quantify and measure the fairness of higher education, it is possible to use data to analyze the fairness of funding for higher education students.

\footnotetext{
${ }^{1}$ Due to the update of statistical information, the author failed to find the student financial support data from 2014 to 2016 in the Statistical Yearbook and related databases.
} 


\section{Data Sources}

According to the definition of the above, the higher education schools in this article refer to general higher education schools, general colleges, and ordinary higher vocational schools, excluding adult institutions of higher learning. In this paper, the sources of higher education student funding include the central government, local finance, college business income, and direct loans by financial institutions, excluding social donation form or indirect financing. According to the above concepts, this paper collects the necessary data from China Education Funds Statistical Yearbook, China Education Statistics Yearbook, and the People's Republic of China Bureau of Statistics.

Higher education student financial assistance data comes from support for individuals and families in general higher education schools expenses of China Education Funds Statistical Yearbook, including "award, assistance, loans, subtractions, and exemptions." The number of students enrolled is based on the number of students in colleges and universities recorded on the National Bureau of Statistics of the People's Republic of China. The data of the regional fiscal revenue comes from the general budgetary revenue of the local government in the national data of the People's Republic of China. After the calculation, we obtained the financial situation table of higher education per student funding in various regions of China from 2000 to 2013, namely Table 1 . The formula is as follows:

The amount of higher education per student funding $=$ support for individuals and families in general higher education schools the number of students enrolled in general higher education schools

To present data in a more concise way, all the raw funding data in Table 1 is retained to the integer bit, but the four decimal places are retained in the actual calculation. Due to the lack of 2012 annual data, there is no relevant measurement about data in 2012. Due to the lack of financial support data of higher education students funding in Xinjiang Uygur Autonomous Region in 2004 and in order to ensure the integrity of data and the rigor of measurement, 2003 annual data was used to supplement the data in the actual calculation.

Table 1

Higher Education per Student Funding in Various Regions of China from 2000 to $2013^{2}$ (unit: yuan)

\begin{tabular}{lrrrrrrrrrrrrrrr}
\hline Provinces & 2000 & 2001 & 2002 & 2003 & 2004 & 2005 & 2006 & 2007 & 2008 & 2009 & 2010 & 2011 & 2012 & 2013 \\
\hline Beijing & 344 & 1,694 & 1,676 & 1,791 & 1,817 & 1,900 & 1,845 & 10,229 & 10,635 & 14,400 & 16,614 & 21,901 & - & 25,829 \\
Tianjin & 3,460 & 1,039 & 1,067 & 769 & 944 & 922 & 562 & 3,879 & 4,417 & 4,632 & 6,082 & 6,124 & - & 6,461 \\
Hebei & 717 & 553 & 565 & 581 & 571 & 560 & 493 & 1,685 & 2,420 & 2,327 & 2,382 & 2,654 & - & 3,108 \\
Shanxi & 909 & 767 & 648 & 648 & 556 & 568 & 550 & 1,654 & 2,202 & 2,128 & 2,631 & 2,901 & - & 3,217 \\
Inner & 546 & 596 & 609 & 628 & 603 & 746 & 714 & 2,028 & 2,762 & 2,572 & 3,121 & 3,747 & - & 4,852 \\
Mongolia & & & & & & & & & & & & \\
Liaoning & 579 & 569 & 552 & 518 & 506 & 610 & 543 & 3,108 & 3,543 & 4,293 & 4,641 & 4,587 & - & 4,841 \\
Jilin & 707 & 728 & 739 & 754 & 737 & 790 & 777 & 3,193 & 3,442 & 4,301 & 3,952 & 4,755 & - & 4,869 \\
Heilongjiang & 633 & 651 & 546 & 642 & 586 & 603 & 620 & 2,733 & 2,665 & 3,327 & 3,565 & 3,897 & - & 4,522 \\
Shanghai & 1,981 & 1,136 & 1,092 & 1,049 & 1,199 & 1,304 & 1,382 & 3,889 & 3,954 & 7,081 & 9,589 & 9,441 & - & 6,437 \\
Jiangsu & 657 & 634 & 678 & 631 & 587 & 616 & 610 & 2,916 & 3,207 & 3,286 & 4,156 & 4,497 & - & 5,991 \\
Zhejiang & 835 & 826 & 768 & 857 & 763 & 768 & 773 & 2,964 & 3,364 & 3,539 & 4,207 & 4,670 & - & 5,109 \\
Anhui & 752 & 791 & 774 & 730 & 663 & 689 & 551 & 1,891 & 2,234 & 2,392 & 2,502 & 2,920 & - & 3,484 \\
\hline
\end{tabular}

\footnotetext{
${ }^{2}$ Before and after 2006, statistics in China's Education Funding Yearbook have caliber differences, from "scholarships" to "subsidies for individual and family expenses," value of number have great changes. However, this study measured and investigated on the annual data, which will not affect the actual results.
} 
(Table 1 to be continued)

\begin{tabular}{lllllllllllllll}
\hline Fujian & 771 & 798 & 764 & 815 & 696 & 865 & 851 & 2,575 & 3,103 & 2,803 & 3,755 & 3,664 & - & 4,173 \\
Jiangxi & 525 & 513 & 502 & 476 & 380 & 358 & 363 & 1,304 & 1,947 & 1,896 & 2,624 & 2,616 & - & 3,195 \\
Shandong & 706 & 728 & 736 & 713 & 629 & 482 & 441 & 2,020 & 2,274 & 2,317 & 2,730 & 3,048 & - & 3,470 \\
Henan & 680 & 704 & 697 & 684 & 602 & 616 & 536 & 1,275 & 1,721 & 1,735 & 1,903 & 2,178 & - & 2,426 \\
Hubei & 483 & 506 & 478 & 469 & 465 & 475 & 422 & 2,457 & 3,117 & 3,663 & 4,122 & 4,093 & - & 4,654 \\
Hunan & 494 & 468 & 408 & 385 & 401 & 459 & 448 & 1,879 & 2,614 & 2,540 & 2,759 & 3,295 & - & 3,968 \\
Guangdong & 708 & 601 & 582 & 550 & 517 & 556 & 589 & 2,617 & 2,967 & 3,420 & 3,891 & 4,150 & - & 4,664 \\
Guangxi & 370 & 341 & 391 & 414 & 439 & 444 & 465 & 1,951 & 2,432 & 2,449 & 2,819 & 3,149 & - & 4,240 \\
Hainan & 983 & 754 & 668 & 700 & 484 & 481 & 395 & 1,070 & 1,599 & 1,306 & 1,963 & 2,174 & - & 1,904 \\
Chongqing & 490 & 496 & 460 & 490 & 452 & 487 & 519 & 2,648 & 3,126 & 3,412 & 3,140 & 4,291 & - & 3,998 \\
Sichuan & 563 & 563 & 552 & 486 & 479 & 448 & 464 & 2,145 & 2,616 & 3,582 & 3,049 & 3,840 & - & 3,920 \\
Guizhou & 596 & 505 & 484 & 641 & 585 & 574 & 607 & 1,830 & 2,949 & 2,821 & 2,999 & 3,681 & - & 4,131 \\
Yunnan & 614 & 593 & 635 & 545 & 552 & 502 & 624 & 2,570 & 3,426 & 3,069 & 3,108 & 3,784 & - & 4,039 \\
Tibet & 604 & 994 & 299 & 246 & 95 & 959 & 200 & 2,750 & 3,942 & 4,890 & 4,936 & 6,455 & - & 6,778 \\
Shanxi & 672 & 694 & 593 & 650 & 536 & 645 & 578 & 2,700 & 3,344 & 4,042 & 4,076 & 4,272 & - & 4,854 \\
Gansu & 748 & 660 & 671 & 654 & 636 & 705 & 584 & 2,287 & 2,767 & 2,607 & 2,754 & 3,058 & - & 3,451 \\
Qinghai & 490 & 443 & 440 & 427 & 372 & 462 & 520 & 4,088 & 4,998 & 4,978 & 5,274 & 5,899 & - & 6,136 \\
Ningxia & 575 & 573 & 424 & 295 & 490 & 462 & 551 & 2,496 & 3,155 & 2,883 & 3,287 & 3,988 & - & 3,854 \\
Xinjiang & 407 & 386 & 314 & 315 & - & 350 & 398 & 2,040 & 2,872 & 3,087 & 4,637 & 5,320 & - & 5,932 \\
\hline
\end{tabular}

\section{Empirical Analysis of the Differences in the Student Financing of Higher Education in China Under the Perspective of Horizontal Equity}

Based on the above analysis, we can carry out empirical research on the fairness of higher education students funding in China from three aspects: horizontal fairness, longitudinal fairness, and fiscal neutrality principle. In the study of longitudinal fairness abroad, there are two methods of measuring longitudinal fairness. The first method is that in combination with horizontal fairness and longitudinal fairness, under the premise that the weight coefficient of students who need to provide additional educational resources, the weighted financial expenditure is used to measure whether fair, this method is used in the study of the learning disabled students abroad more common. The second is on the premise of there are differences in the education financial price, remove the additional education resources and specialized investment funds from the total input, through the education financial resources price index and education finance special income to measure the fairness of education. However, due to the fact that the education financial input of students in the higher education stage is not applied with different weight coefficient and there is no unified price index of education resources, so it is difficult to carry out the longitudinal equity research of higher education students under the existing conditions. Therefore, this paper will proceed from the principle of horizontal fairness and carry out empirical research on the funding of higher education students in China.

\section{Evaluation Index Construction}

The principle of horizontal fairness refers to the provision of equal educational resources for students of the same condition and is also regarded as the principle of equal distribution of resources. Each student should receive an equal allocation of resources, that is, students who receive education funding, regardless of their personal conditions, should receive the same amount of funding. There are many indicators that can measure horizontal fairness, such as range, variance, standard deviation, coefficient of variation, Mcloone index, Verstegen index, Gini coefficient, Theil coefficient, etc. This paper comprehensively compares the basic 
characteristics and applicable ranges of each coefficient, as shown in Table 2. As can be seen from Table 2, the Mcloone index, the Verstegen index, the Gini coefficient, and the Theil coefficient are suitable for measuring the gap between rich and poor and the distribution of resources among different groups. The Mcloone index and the Verstegen index are used to reflect the discrete degree of median up and down observed values. The Gini coefficient can be used to measure the specific difference of regional resource allocation with relatively standardized values. The Theil coefficient can reflect interregional and regional differences.

Table 2

Selectable Indicators of Horizontal Fairness and the Main Characteristics

\begin{tabular}{|l|l|l|}
\hline Index & Basic characteristics & Range of application \\
\hline Range & $\begin{array}{l}\text { Range, the difference between the maximum and minimum } \\
\text { values of the sample data reflects the degree of discretization } \\
\text { of the partial sample data. }\end{array}$ & Suitable for small sample size $(N<10)$. \\
\hline $\begin{array}{l}\text { Variance and } \\
\text { standard deviation }\end{array}$ & $\begin{array}{l}\text { To measure the difference between each variable (observed } \\
\text { value) and the total mean, the standard deviation is the } \\
\text { arithmetic square root of the variance, and the two are the } \\
\text { most commonly used methods for measuring numerical data. }\end{array}$ & $\begin{array}{l}\text { For more extreme observations of the data, } \\
\text { usually by randomly extracting a certain } \\
\text { number of samples to calculate the variance, } \\
\text { the standard deviation, in order to infer the } \\
\text { overall degree of dispersion. }\end{array}$ \\
\hline $\begin{array}{l}\text { Coefficient of } \\
\text { variation }\end{array}$ & $\begin{array}{l}\text { The ratio of the standard deviation of the original data to the } \\
\text { mean of the original data is able to eliminate the influence of } \\
\text { the measurement scale and dimension, but it is easy to } \\
\text { increase the weight of the two extremes. }\end{array}$ & $\begin{array}{l}\text { Suitable for comparing the size of the two sets } \\
\text { of data discretization. }\end{array}$ \\
\hline Mcloone index & Reflect the fairness of the observed values below the median. & $\begin{array}{l}\text { The two are suitable for use together to reflect } \\
\text { the inequality between different groups. }\end{array}$ \\
\hline Verstegen index & Reflect the fairness of the observed values above the median. & $\begin{array}{l}\text { Measure the income gap or the gap between } \\
\text { rich and poor, there is a recognized fairness of } \\
\text { the international standards. }\end{array}$ \\
\hline Gini coefficient & $\begin{array}{l}\text { Describe the size of the allocation of resources in different } \\
\text { regions and people. }\end{array}$ & $\begin{array}{l}\text { Measure interregional and regional } \\
\text { differences. }\end{array}$ \\
\hline Theil coefficient & $\begin{array}{l}\text { Can be multi-level (intra-group) decomposition by regional } \\
\text { structure, weighted by economies of scale. }\end{array}$ \\
\hline
\end{tabular}

To present the research question as comprehensively and accurately as possible, comprehensively and accurately present the perspective of the research question, according to the previous research results of scholars, the characteristics of the study data, and the necessity of interpretation of the results, this paper finally chose Mcloone index, Verstegen index, Gini coefficient, and Theil coefficient as the main indicators of higher education student funding horizontal fairness.

The Mcloone index. A measurement method based on the measurement of the data distribution below the median of the sample data, which can reflect the fairness of the observed values below the median. The Mcloone index is equal to the sum of the data below the median divided by the sums of these observations equal to the median (Wu \& Zheng, 2009). In general, the Mcloone index is between 0 and 1, and there is no absolute criterion. The smaller the Mcloone index is, the greater the inequality between the median and low-level groups and the lower the degree of fairness are. When the index is larger, the inequality between the median and low-level groups is smaller, that is, the degree of fairness is higher. When the Mcloone index (Wu $\&$ Zheng, 2009) is higher than 0.95 , an ideal state of fairness is considered.

$$
\text { Mcloone }=\left(\sum_{i=1}^{j} P_{i} X_{i}\right) / M_{p} \sum_{i=1}^{j} P_{i}
$$

$X_{i}(i=I, L, J)$ represents a sample of all sample observations below the median in ascending order. 
Suppose the sample has $m, P_{i}=$ the number of students in the region $i, X_{i}=$ the average amount of higher education student funding in the region $I$, and $M_{p}=$ the median amount of higher education student funding. The median funding of the higher education students in all regions of our country is arranged in ascending order and the median is calculated. Then, the sum of the higher education students funding in the areas below the median amount is obtained, and then, divided by the $m$ times of the median. We can get the Mcloone index about the median funding of the higher education students in all regions of our country.

The Verstegen index. It is an inverse of the Mcloone index used to reflect the discrepancy of the observed value above the median and can be used to reflect the gap between the high-level and medium-level groups. The Verstegen index is equal to the sum of the observed values above the median divided by the sums of these observations equal to the median. The value of the Verstegen index is greater than 1 and when the Verstegen index is closer to 1 , the smaller the inequality of the median and high-level groups is, the higher the degree of fairness is.

$$
\text { Verstegen }=\left(\sum_{i=k}^{N} P_{i} X_{i}\right) / M_{p} \sum_{i=k}^{N} P_{i}
$$

$X_{i}(i=K, L, N)$ represents a sample of all sample observations above the median in ascending order. Suppose the sample has $t, P_{i}=$ the number of students in the region $I, X_{i}=$ the average amount of higher education student funding in the region $I, M_{p}=$ the median of the average amount of higher education student funding. The median funding of the higher education students in all regions of our country is arranged in ascending order and the median is calculated. Then, the sum of the higher education students funding in the areas above the median amount is obtained, and then divided by the t times of the median. We can get the Verstegen index about the average funding of the higher education students in all regions of our country.

The Gini coefficient. It is a method for comparing the allocation of resources of different regions and populations developed by the concept of the Lorenz curve, initially to measure the income gap between residents. The Lorenz curve refers to sorting the observed values in the order from small to large and take the percentage of cumulative number of the observed values as the horizontal axis, take the percentage of cumulative sum of the observed values as the vertical axis. If the allocation is absolute, then the proportion of the observed value is exactly equal to the corresponding number, and the Lorenz curve that is the diagonal, which is also called the absolute average (Wu \& Zheng, 2009). The meaning of the Gini coefficient is the area A surrounded by the absolutely fair line and the Lorenz curve line accounts for the proportion of the area between the absolute unfair line and absolute fair line $(A+B)$. Figure 1 is the Gini coefficient calculation diagram. The formula is expressed as follows:

$$
\text { Gini }=\frac{A}{A+B}
$$

Gini coefficient has a variety of calculation methods, taking into account of the similarity among research questions. This paper uses the method used by Ye and Zhang (2007) in the measurement of Gini coefficient of basic education. First calculate the proportion of the total funding of average funding of the higher education students in each region to the total income of the whole country, set as $W_{i}$. And calculate the proportion of the number of students enrolled in the institutions of higher education in each region to the number of students in the general colleges and universities in the whole country, set as $P_{i}$. And then arrange all regions of average 
funding of the higher education students in ascending order. Calculate the Gini coefficient according to the following calculation formula:

$$
\text { Gini }=1-\sum_{i=1}^{n} P\left(2 Q_{i}-W_{i}\right), \text { where } Q_{i}=\sum_{k=1}^{i} W_{k}
$$

When the Gini coefficient equal to 0 means completely fair, equal to 1 means completely unfair. The relevant organizations of the United Nations provides the corresponding standards: If the Gini coefficient below 0.2 that is absolutely equal, when the value is in the range of 0.2 to 0.3 that is relatively average, in the range of 0.3 to 0.4 that is reasonable, in the range of 0.4 to 0.5 that the income gap is large, and above 0.6 that is wide income gaps. Internationally, they recognized 0.4 as "cordon." Although in the field of education, not necessarily fully applicable to international standards, but it can be used as a valuable reference. At the same time, the National Bureau of Statistics published 2000-2013 Gini coefficient in China as shown in Table 3 (Statistics Bureau, 2013), which can also be used as a reference for this study.

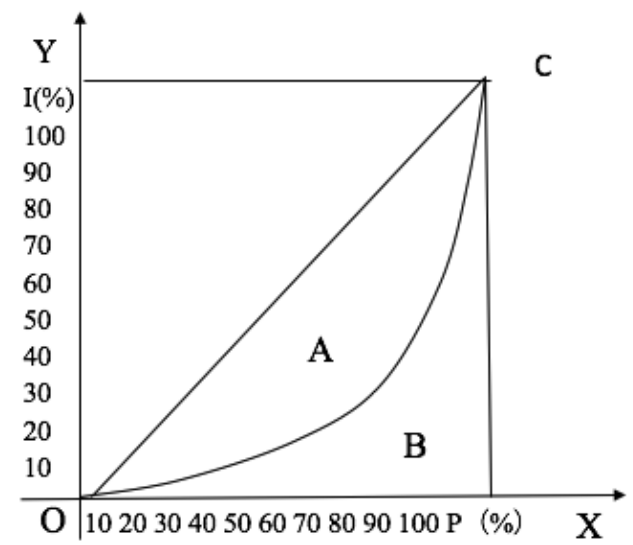

Figure 1. Gini coefficient calculation diagram.

Table 3

China's 2000-2013 Gini Coefficient

\begin{tabular}{lllllllllllllll}
\hline Year & 2000 & 2001 & 2002 & 2003 & 2004 & 2005 & 2006 & 2007 & 2008 & 2009 & 2010 & 2011 & 2012 & 2013 \\
\hline Gini & 0.412 & 0.490 & 0.454 & 0.479 & 0.473 & 0.485 & 0.487 & 0.484 & 0.491 & 0.490 & 0.481 & 0.477 & 0.474 & 0.473 \\
\hline
\end{tabular}

Theil coefficient. It is created by Thiel (1967) who uses the concept of entropy in information theory to calculate the inequality of income. The Theil coefficient is a special case of the application of the entropy index. It can decompose the regional differences according to the regional structure in multiple levels (within or between groups), then weighted by the economic scale. The expression for the Theil coefficient is:

$$
T=\frac{1}{n} \sum_{i=1}^{n} \frac{y_{i}}{\bar{y}} \ln \left(\frac{y_{i}}{\bar{y}}\right)
$$

$y_{i}$ represents the income of individual $i$, which is the average funding of the higher education students of the province $I, \bar{y}$ represents the average income of all individuals, that is, the average amount of the average funding of the higher education students in all provinces. For the grouping formula, the Theil coefficient has another expression:

$$
T=\sum_{k=1}^{k} w_{k} \ln \left(\frac{w_{k}}{e_{k}}\right)
$$


Where $w_{k}$ represents the proportion of income in the kth group to the total income, that is, the proportion of average funding of the higher education students in the kth group to the total amount. The $e_{k}$ represents the proportion of the population of the kth group to the total population, that is, the proportion of the number of students in the kth group to the total number of students in general colleges and universities (Sun, 2009).

According to the regional distribution standards formulated by the National Bureau of Statistics of the People's Republic of China (see Table 4). Due to the regional classification not only takes into account the regional geographical location of our provinces and also takes into account the degree of economic development, it has a certain representation. Therefore, based on Table 4, we use the Theil coefficient calculation method to calculate the average funding of the higher education students in our country.

Table 4

\section{Distribution of Regional Provinces in China}

\begin{tabular}{ll}
\hline Regions & Contained Provinces \\
\hline North China & Beijing, Tianjin, Hebei, Shanxi, and Inner Mongolia \\
Northeast area & Heilongjiang, Jilin, and Liaoning \\
East China & Shanghai, Jiangsu, Zhejiang, Anhui, Fujian, Jiangxi, and Shandong \\
Central and Southern China & Henan, Hubei, Hunan, Guangdong, Guangxi, and Hainan \\
Southwest China & Chongqing, Sichuan, Guizhou, Yunnan, and Tibet \\
Northwest China & Shanxi, Gansu, Qinghai, Ningxia, and Xinjiang \\
\hline
\end{tabular}

\section{Analysis of the Evaluation Indicators Calculation Results}

Analysis based on the Mcloone index and the Vestegen index. The Mcloone index and the Vestegen index of the average amount of higher education student funding in China from 2000 to 2013 are calculated by the method described above, the result is shown in Table 5. The data of funding for higher education schools are derived from the individual and family subsidies of Statistical Yearbook of China's Education Fund (2001-2014), the number of students enrolled in ordinary high school comes from the National Bureau of Statistics of the People's Republic of China National Statistics (2000-2013).

Table 5

The Mcloone and Vestegen Index of the Average Amount of Higher Education Student Funding of China in 2000-2013

\begin{tabular}{lllllllllllllll}
\hline Year & 2000 & 2001 & 2002 & 2003 & 2004 & 2005 & 2006 & 2007 & 2008 & 2009 & 2010 & 2011 & 2012 & 2013 \\
\hline Mcloone & 0.783 & 0.830 & 0.851 & 0.772 & 0.839 & 0.840 & 0.847 & 0.747 & 0.789 & 0.750 & 0.804 & 0.783 & - & 0.815 \\
Vestegen & 1.447 & 1.382 & 1.416 & 1.317 & 1.362 & 1.409 & 1.389 & 1.369 & 1.305 & 1.426 & 1.554 & 1.469 & - & 1.470 \\
\hline
\end{tabular}

Figure 2 intuitively reflects the Mcloone index of the average amount of higher education student funding in all regions of China over the years. The overall value of the Mcloone index is roughly in the range of 0.76 to 0.84. As is clear from the above, the Mcloone index closer to 1 means more equitable, if the Mcloone index over 0.95 is an ideal fair state. China's higher education student funding is in a relatively fair state. In the course of historical development, the Mcloone index curve is declining as a whole, that is, the overall inequality of the financing of higher education students in China from 2000 to 2013 has been deepened. However, the Mcloone index curve began to rise in 2011-2013, showing that the problem of fairness of funding for higher education students has been improved in recent years. 


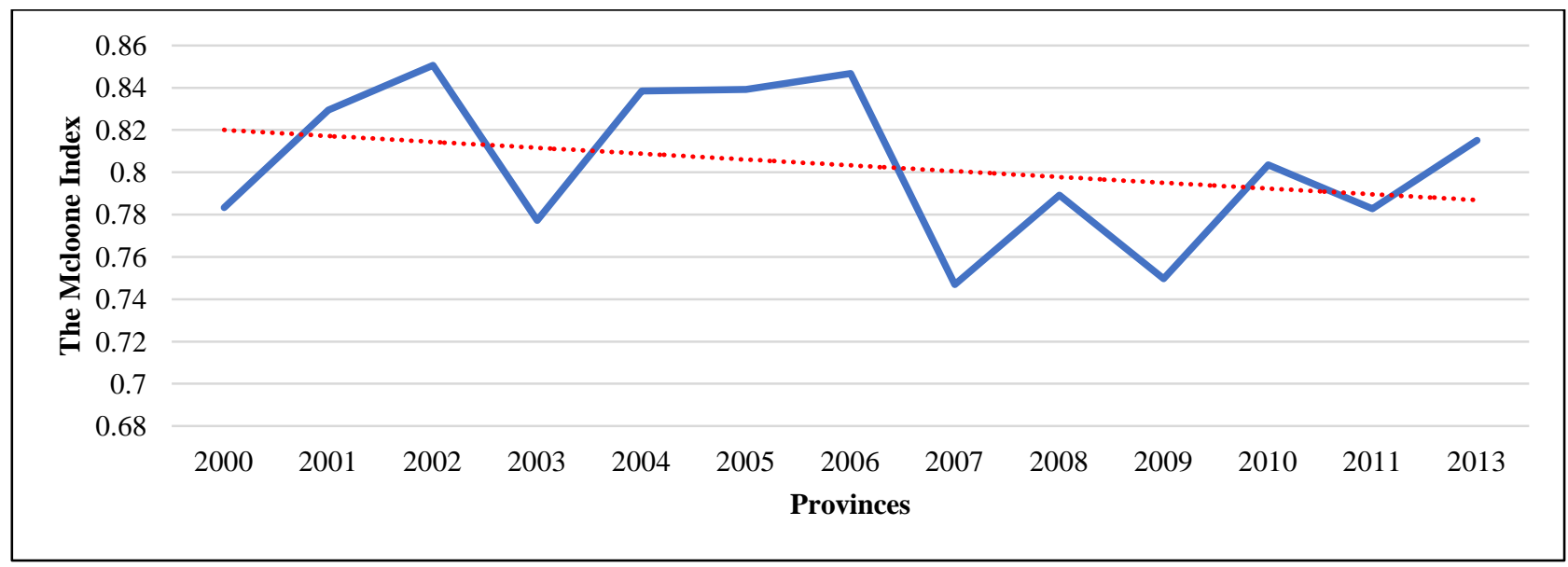

Figure 2. The Mcloone index of the average amount of higher education student funding in all regions of China in 2000-2013.

The Vestegen index of the average amount of higher education student funding in each region from 2000 to 2013 , remained in 1.35 to 1.55 as a whole. As we can see from above, the Vestegen index closer to 1 means more equitable, so the average amount of higher education student funding in our regions is in a relatively fair state. The Vestegen index as a whole is in a steady growth trend. It can be seen that the overall inequality of higher education students in our country is deepened, but similar to the Mcloone index, the rate of increase in 2011-2013 has been slowed down and the unfairness has been improved to some extent (see Figure 3).

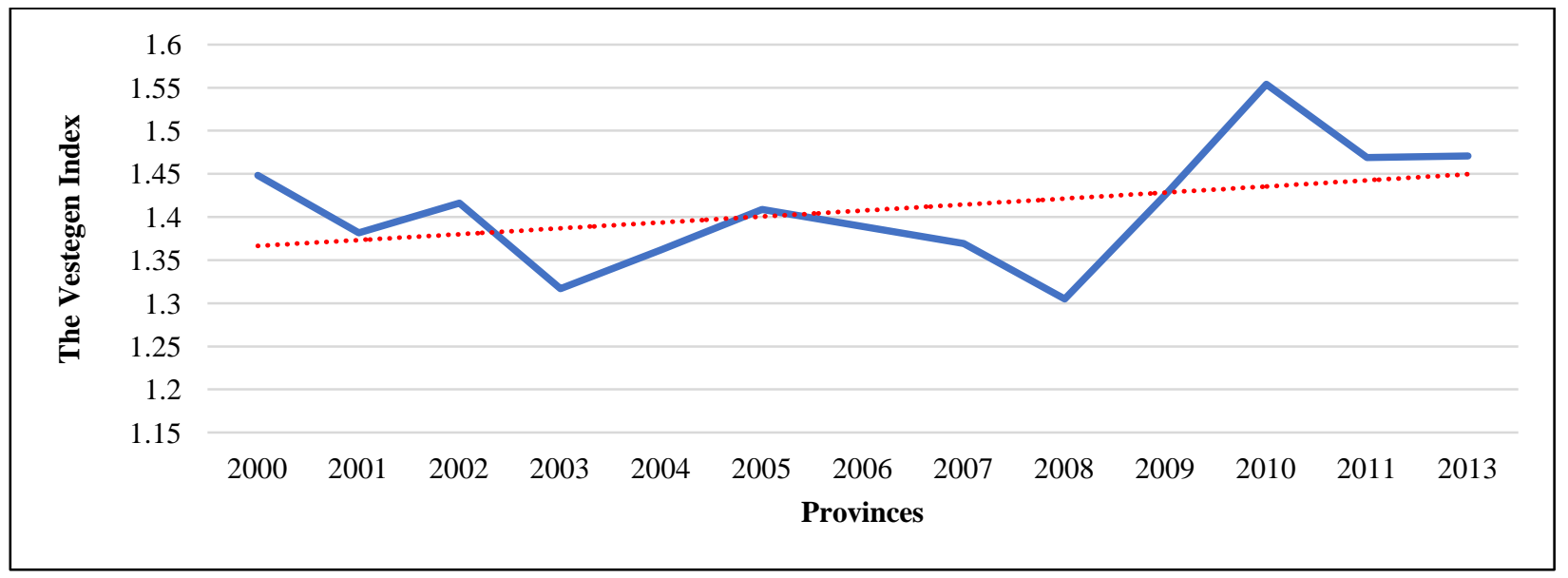

Figure 3. The Vestegen index of the average amount of higher education student funding in 2000-2013.

Analysis based on Gini coefficient. According to the above-mentioned methods, we can calculate the Gini coefficient of higher education students funding in our country. It can be seen from Table 6 and Figure 4 that the Gini coefficient of the average amount of higher education student funding in all regions of China in 2000-2013, remained in 0.17 to 0.24 as a whole, is a relatively average state. According to Table 3 shows that Gini coefficient of China's economic and social development level is about 0.45 up and down, higher education students funded regional differences is far less than the overall economic and social gap in China. From 2001 to 2006, the Gini coefficient of higher education students funding in China was less than 0.2, in a fairly fair state. And the Gini coefficient increased after 2009, the unfairness was deepened, and the Gini coefficient decreased from 2011 to 2013, the problem of inequality is alleviated to some extent. Based on the above study, we can 
find that the trend of Gini coefficient is similar to that of Mcloone index and Vestegen index. That is, education students funding in our country is higher in a fairly fair state, but as time goes on, the imbalance between the regions has deepened and the inequality between regions has been alleviated after 2011.

Table 6

The Gini Coefficient of The Average Amount of Higher Education Student Funding of China in 2000-2013

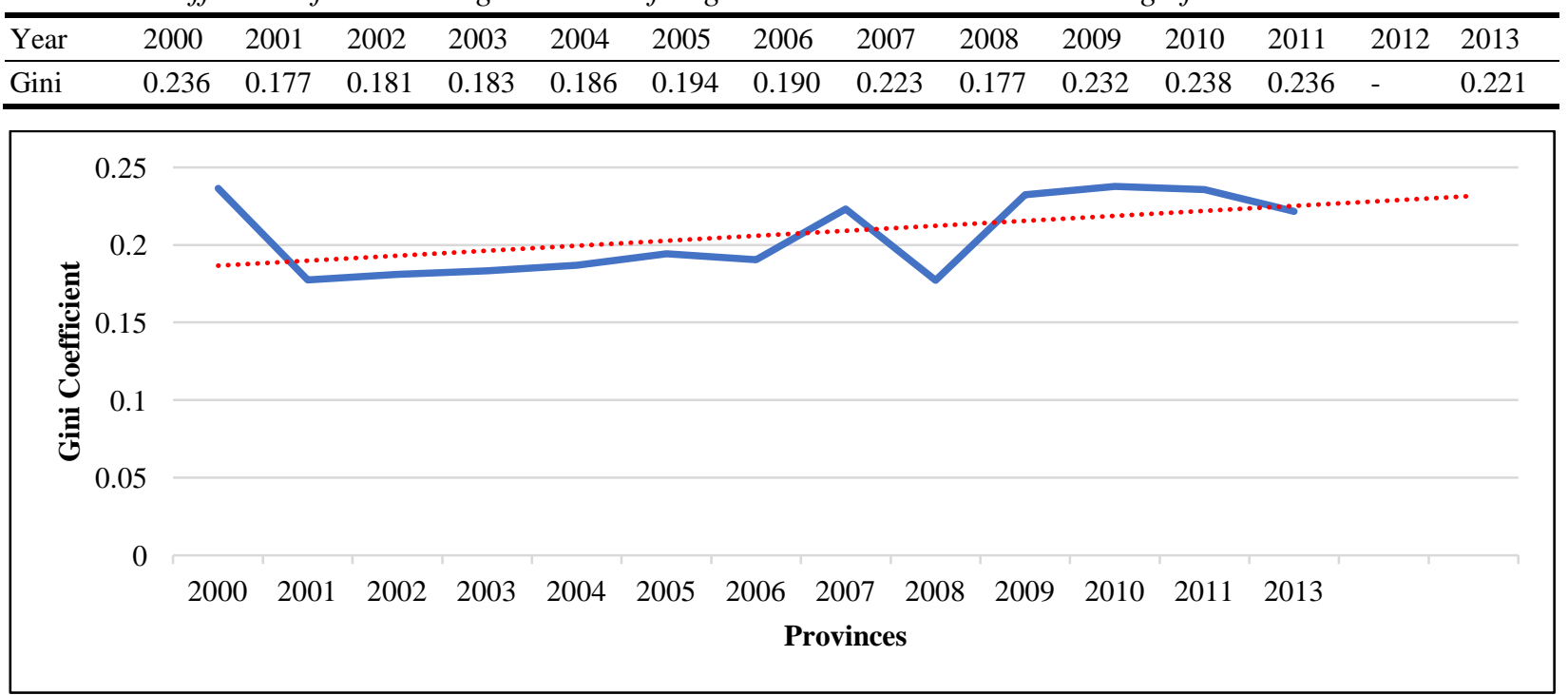

Figure 4. The Gini coefficient of the average amount of higher education student funding of China in 2000-2013.

Analysis based on Theil coefficient. According to the above-mentioned methods, we can calculate Theil coefficient of higher education students funding in North China, Northeast China, East China, Central and Southern China, and Southwest and Northwest China from 2000 to 2013, as shown in Table 7 and Figure 5.

Table 7

Higher Education Students Funding In Each of the Interregional and Regional Sectors from 2000 to 2013

\begin{tabular}{|c|c|c|c|c|c|c|c|}
\hline Region & $\begin{array}{l}\text { Contribution } \\
\text { rate in North } \\
\text { China }\end{array}$ & $\begin{array}{l}\text { Contribution } \\
\text { rate in } \\
\text { Northeast } \\
\text { China }\end{array}$ & $\begin{array}{l}\text { Contribution } \\
\text { rate in East } \\
\text { China }\end{array}$ & $\begin{array}{l}\text { Contribution } \\
\text { rate in Central } \\
\text { and Southern } \\
\text { China }\end{array}$ & $\begin{array}{l}\text { Contribution } \\
\text { rate in } \\
\text { Southwest } \\
\text { China }\end{array}$ & $\begin{array}{l}\text { Contribution } \\
\text { rate in } \\
\text { Northwest } \\
\text { China }\end{array}$ & $\begin{array}{l}\text { Group } \\
\text { contribution } \\
\text { rate }\end{array}$ \\
\hline 2000 & 0.539 & 0.002 & 0.161 & 0.046 & 0.002 & 0.016 & 0.235 \\
\hline 2001 & 0.340 & 0.008 & 0.111 & 0.086 & 0.096 & 0.053 & 0.307 \\
\hline 2002 & 0.318 & 0.014 & 0.085 & 0.058 & 0.049 & 0.060 & 0.417 \\
\hline 2003 & 0.327 & 0.014 & 0.086 & 0.056 & 0.064 & 0.086 & 0.367 \\
\hline 2004 & 0.308 & 0.012 & 0.138 & 0.014 & 0.129 & 0.039 & 0.360 \\
\hline 2005 & 0.340 & 0.010 & 0.219 & 0.013 & 0.078 & 0.048 & 0.292 \\
\hline 2006 & 0.370 & 0.012 & 0.258 & 0.016 & 0.081 & 0.013 & 0.250 \\
\hline 2007 & 0.576 & 0.002 & 0.089 & 0.053 & 0.013 & 0.044 & 0.222 \\
\hline 2008 & 0.566 & 0.009 & 0.068 & 0.051 & 0.019 & 0.053 & 0.235 \\
\hline 2009 & 0.550 & 0.005 & 0.151 & 0.056 & 0.022 & 0.034 & 0.182 \\
\hline 2010 & 0.520 & 0.004 & 0.191 & 0.040 & 0.022 & 0.028 & 0.197 \\
\hline 2011 & 0.582 & 0.002 & 0.120 & 0.025 & 0.023 & 0.023 & 0.215 \\
\hline 2012 & - & - & - & - & - & - & - \\
\hline 2013 & 0.620 & 0.0003 & 0.040 & 0.039 & 0.022 & 0.022 & 0.257 \\
\hline
\end{tabular}




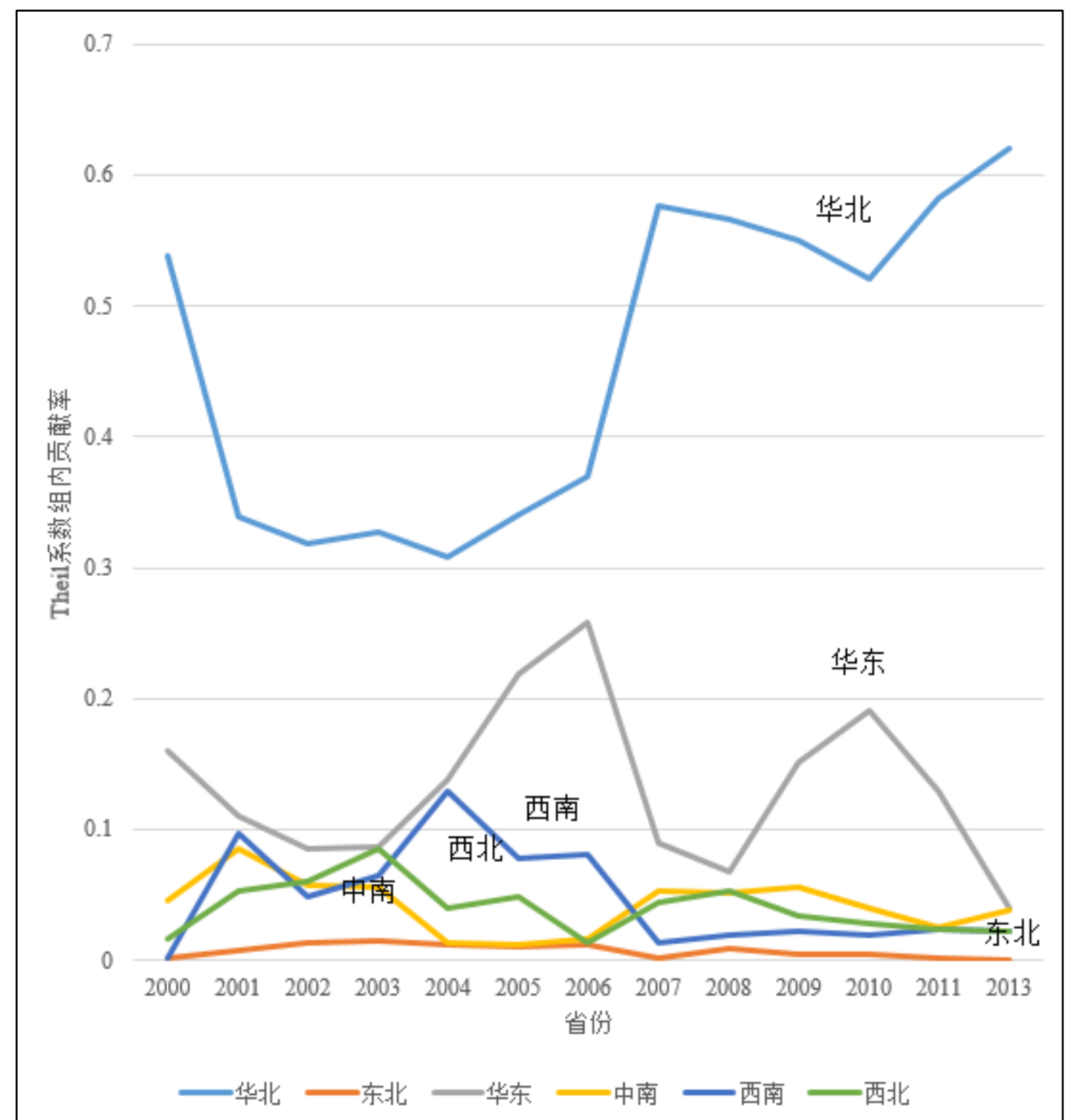

Figure 5. Theil coefficient of China's higher education students funding contribution rate within groups from 2000 to 2013.

From Figure 5, we can see that the differences between the two regions in 2000-2003 are gradually reduced. Around 2002, the difference among the five regions was the most obvious, at about $45 \%$, followed by differences gradually reduced, keeping stable at about $30 \%$, the higher education students funding among five regions is becoming more and more fair (Liang \& $\mathrm{Hu}, 2012)$.

\section{Conclusions}

Firstly, in general, China's higher education students funding is in a relatively fair state. According to the above study, we can see that the Mcloone index is $0.76-0.84$, which is close to 0.95 and the Verstege index is between 1.35 and 1.55, which is close to the fair state 1 . The Gini coefficient is between 0.17 and 0.24 , also close to the average range $0.2-0.3$. We can see that China's higher education student funding is generally in a more equitable state. From Table 3, we can see that the Gini coefficient of China's economic development is 
about 0.45 , and the higher education students funded regional differences is far less than the overall economic and social wealth gap in China. In addition to Beijing, Tianjin, Shanghai, and other regions have significant differences, in general, China's higher education students funded regional differences are not very significant. Therefore, China's higher education students funding are in a more fair state.

Secondly, the subsidy of higher education students in China from 2000 to 2013 has shown an increasingly unfair trend, but after 2011, the unfair trend has eased. According to the above study, we can find that the Mcloone index of the higher education students funding in China is in a downward trend from 2000 to 2013, and the Verstege index and the Gini coefficient are on the rise. The three sets of indicators show that the differences of the higher education students funding among various regions are gradually increasing, the degree of inequality has been deepened. However, since the beginning of 2011, the three sets of curves have a tendency to reverse in the opposite direction to the overall trend. So, it can be seen that after 2011, China's higher education students funded regional differences gradually reduced, the fair trend is gradually obvious.

Thirdly, the subsidy of higher education students in our country is highly correlated with the regional financial and economic development level. As time goes on, the influence of regional fiscal revenue on the financing of higher education students is more and more obvious, which is contrary to the financial neutrality principle in the theory of educational fiscal fairness. It is not difficult to find that the higher education students funding in our country are highly correlated with the regional finance. When other conditions remain the same, the per capita revenue increases by $1 \%$ during the period from 2000 to 2013, the amount of higher education per student funding will grow about $0.7 \%$ to $0.9 \%$. So, the subsidy of higher education students in our country is highly correlated with the regional economic development level. According to the rising trend of the elastic coefficient curve, it can be found that the effect of regional fiscal revenue on the higher education students funding is becoming more and more obvious over time, so that the impact of regional fiscal revenue on the development of higher education students funding is more and more obvious. It can be seen that the funding of higher education students is more and more affected by the regional economic development level. From the perspective of fiscal neutrality, the funding of higher education students in China is highly correlated with regional fiscal revenue, which is contrary to educational equity.

Fourthly, the differences in the funding of higher education students in China are more obvious in different regions. Among them, there are significant differences in North China and East China, and the internal differences in the northeast China are the least obvious. From above study and the calculation results of the Theil coefficients in the five regional groups of our country, differences can be found that there are significant differences in the area of higher education in China and there are significant differences among different regions. The differences in the area of North China and the East China region are the most significant difference. In summary, we are not hard to find that, due to the average amount of the higher education students funding in Beijing, Tianjin, and Shanghai are the highest level, much higher than the area in other provinces and regions, so the internal differences are significant. In the central and southern China and northeast regions, the difference in funding for higher education students in the region is small, and the funding of higher education students in the provinces is relatively average.

\section{References}

Ding G. L., Jiang X. P., \& Yang Z. D. (2009). The implementation status and countermeasures of green channel in universities. Education and occupation, 30, 159-160. 
Liang, W. Y., \& Hu, Y. M. (2012). The measure and regional difference analysis on the research innovation ability of natural sciences in Project 211 university-Based on the osculating value model and decomposition of Theil-Index. China Higher Education Research, 10, 9-14.

Prashant, L., Song, Y., \& Wei, J. G. (2011). An evaluation on China's current policy concerning undergraduate student financial aid. Peking University Education Review, 1, 68-79.

Rong, Z. K., \& Liu, H. (2012). Suggestions for free normal education policy and its implementation: A comparison between policy of free normal education and that of national defense student policy. Education development research, 18, 13-16.

Statistics Bureau. (2013). Last year the Gini coefficient is 0.474, income distribution reform became more urgent. Retrieved from http://finance.chinanews.com/cj/2013/01-18/4500444.shtml

Sun, X. (2009). The differences in educational attainment and the decomposition in China. Statistics and Information Forum, 3 , 87-91.

Wu, C. X., \& Zheng, X. P. (2009). Evaluation and empirical study of education financial equity in China. Statistics and Decision, 9, 123-125.

Ye, P., \& Zhang, C. P. (2007). Re-investigation on Gini coefficient of public outlay within average budget of basic education, and the discussion with professor Yang Yingxiu. Education Research, 2, 48-55. 